\title{
TEKNIK TELAAH SOAL UJI KOMPETENSI PEREKAM MEDIS DAN PENGGUNAAN APLIKASI UJIAN ONLINE DI MASA PANDEMI
}

\author{
Nanda Aula Rumana ${ }^{1}$, Laela Indawati ${ }^{2}$, Deasy Rosmala Dewi ${ }^{3}$, Daniel Happy Putra ${ }^{4}$, Puteri \\ Fannya $^{5}$ \\ ${ }^{1,2,3,4,5)}$ Program Studi Rekam Medis dan Informasi Kesehatan, Fakultas Ilmu-ilmu Kesehatan, \\ Universitas Esa Unggul \\ e-mail: nanda.rumana@esaunggul.ac.id
}

\begin{abstract}
Abstrak
Tenaga kesehatan merupakan seseorang yang mengabdikan dirinya pada bidang. Salah satu tenaga kesehatan diantaranya adalah petugas rekam medis dan informasi kesehatan. Seorang perekam medis dan informasi kesehatan harus mempunyai kompetensi yang baik, perekam medis dan informasi kesehatan diharuskan mampu melakukan tugas dalam memberikan pelayanan rekam medis dan informasi kesehatan yang bermutu tinggi dengan memperlihatkan beberapa kompetensi. Untuk menghadapi uji kompetensi tenaga kesehatan tersebut, selain dari sisi peserta didik harus mempersiapkan diri dengan belajar dan berlatih, tenaga dosen juga harus membuat soal yang landasannya berdasarkan format soal uji kompetensi. Maka dari itu, diperlukan telaah soal sebagai upaya institusi pendidikan sehingga setiap dosen mampu menghasilkan soal-soal untuk mencapai kompetensi mata kuliah secara optimal, mempunyai validitas yang tinggi dengan analisis yang dapat diterima secara nasional serta dapat terbentuk bank soal sebagai persiapan uji kompetensi. Pengabdian ini dilaksanakan melalui video conference (via aplikasi zoom) pada 15 Juli 2020 dikarenakan wabah pandemi Covid-19. Selain itu, kegiatan juga disiarkan secara live dalam platform youtube. Output dalam kegiatan ini diharapkan keterampilan dosen setelah diberikan materi tentang teknik telaah soal uji kompetensi perekam medis dan penggunaan aplikasi ujian online meningkat. Sehingga pada masa mendatang dosen tidak mengalami kesalahan pada saat pembuatan soal.
\end{abstract}

Kata kunci: Uji Kompetensi, Perekam Medis, Exit Exam

\begin{abstract}
A health worker is someone who devotes himself to the field. One of the health workers is a medical record and health information officer. A medical recorder and health information must have good competence, a medical recorder and health information is required to be able to perform the task of providing high quality medical record and health information services by demonstrating several competencies. To face the competency test of health workers, apart from students having to prepare themselves by studying and practicing, lecturers also have to make questions based on the format of competency test questions. Therefore, it is necessary to study questions as an effort by educational institutions so that each lecturer is able to produce questions to achieve subject competence optimally, have high validity with nationally acceptable analysis and a question bank can be formed as preparation for competency tests. This service was carried out via video conference (via the zoom application) on July 15, 2020 due to the COVID-19 pandemic. In addition, the activity was also broadcast live on the YouTube platform. The output in this activity is expected to increase the lecturer's skills after being given material on the technique of reviewing medical recorder competency test questions and increasing the use of online exam applications. So that in the future the lecturer will not experience errors when making questions.
\end{abstract}

Keywords: Competency Test, Medical Recorder, Exit Exam 


\section{PENDAHULUAN}

Tenaga kesehatan merupakan seseorang yang mengabdikan dirinya pada bidang kesehatan serta memiliki pengetahuan dan kemampuan melalui pendidikan dibidang kesehatan serta pada jenis tenaga kesehatan tertentu memerlukan kewenangan untuk melakukan upaya kesehatan (Presiden RI, 2014). Salah satu tenaga kesehatan diantaranya adalah petugas rekam medis dan informasi kesehatan. Perekam medis dan informasi kesehatan adalah seseorang yang sudah menyelesaikan pendidikan Rekam Medis dan Informasi Kesehatan di institusi pendidikan sesuai ketentuan perundangan yang berlaku (Kemenkes, 2013).

Seorang perekam medis dan informasi kesehatan harus mempunyai kompetensi yang baik, perekam medis dan informasi kesehatan diharuskan mampu melakukan tugas dalam memberikan pelayanan rekam medis dan informasi kesehatan yang bermutu tinggi dengan memperlihatkan beberapa kompetensi. Tujuh kompetensi perekam medis diantaranya profesionalisme yang luhur, etika dan legal, mawas diri serta pengembangan diri, komunikasi yang efektif, manajemen data dan informasi kesehatan, keterampilan klasifikasi klinis, kodifikasi penyakit dan masalah kesehatan lainnya, serta prosedur klinis, aplikasi statistik kesehatan, epidemiologi dasar, dan biomedik, serta manajemen pelayanan RMIK (Kemenkes, 2020).

Pendidikan yang bermutu akan menghasilkan lulusan yang berkualitas dan memiliki daya saing tinggi, sesuai dengan kompetensinya. Berdasarkan Peraturan Menteri Kesehatan Republik Indonesia nomor 83 tahun 2019 tentang Registrasi Tenaga Kesehatan disebutkan bahwa setiap tenaga kesehatan yang akan melaksanakan pekerjaannya wajib memiliki STR (Surat Tanda Registrasi) (Kemenkes, 2019). Untuk memperoleh STR, tenaga kesehatan harus memiliki ijazah dari institusi pendidikan dan sertifikat kompetensi dari konsil tenaga kesehatan masing-masing. Ijazah dan sertifikat kompetensi diberikan kepada peserta didik setelah dinyatakan lulus ujian program pendidikan dan uji kompetensi.

Untuk menghadapi uji kompetensi tenaga kesehatan tersebut, selain dari sisi peserta didik harus mempersiapkan diri dengan belajar dan berlatih, tenaga dosen juga harus membuat soal yang landasannya berdasarkan format soal uji kompetensi. Maka dari itu, diperlukan telaah soal sebagai upaya institusi pendidikan sehingga setiap dosen mampu menghasilkan soal-soal untuk mencapai kompetensi mata kuliah secara optimal, mempunyai validitas yang tinggi dengan analisis yang dapat diterima secara nasional serta dapat terbentuk bank soal sebagai persiapan uji kompetensi. Soal yang telah ditelaah, akan diimplementasikan kedalam aplikasi ujian online sebagai alternative media penilaian ujian secara elektronik yang mempunyai keunggulan sehingga dapat memudahkan untuk mendapatkan nilai dan mengaudit soal-soal yang perlu dievaluasi.

Uji kompetensi perekam medis sudah dilaksanakan semenjak tahun 2018, setiap tahun angka kelulusan mahasiswa rekam medis yang memiliki hasil yang cukup fluktuatif seperti pada gambar berikut ini:

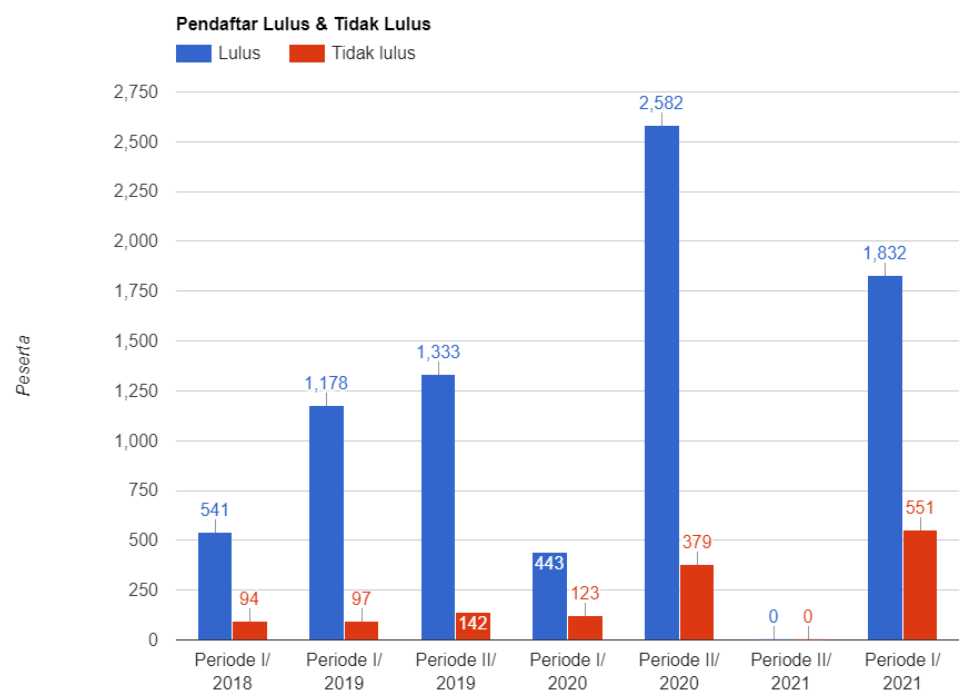

Gambar 1. Tingkat Kelulusan Uji Kompetensi Prodi Rekam Medis dan Informasi Kesehatan Sumber: Uknakes Kemdikbud 2021 
Berdasarkan gambar 1 terlihat bahwa tingkat ketidaklulusan mahasiswa rekam medis dalam uji kompetensi memberikan tren yang semakin meningkat dari tahun 2019-2021. Ada berbagai macam faktor yang menyebabkan mahasiswa gagal dalam menjalankan uji kompetensi, berdasarkan penelitian Andriaty yang meneliti tentang faktor yang menyebabkan kegagalan mahasiswa dalam uji kompetensi dokter Indonesia adalah faktor akademik seperti metode belajar, karakteristik pembelajar dewasa dan faktor non akademik yang terdiri dari faktor non akademik internal seperti motivasi kuliah, konsentrasi belajar, kesehatan, faktor non akademik eksternal seperti lingkungan belajar (Andriaty et al., 2016). Sedangkan faktor yang menyebabkan kelulusan dalam uji kompetensi pada perekam medis adalah faktor kognitif (nilai IPK dan nilai koding) (Nuryati et al., 2020)

Prodi Rekam Medis dan Informasi Kesehatan Universitas Esa Unggul merupakan prodi pelopor berdirinya rekam medis di Indonesia, sudah 4 kali berturut-turut prodi ini mendapatkan akreditasi A. Sejalan dengan predikat akreditasi A, seharusnya lulusan prodi RMIK UEU memiliki kompetensi yang memadai sesuai dengan standar pendidikan. Prodi RMIK UEU berada dibawah naungan LLDIKTI 3, tingkat kelulusan mahasiswa dari LLDIKTI 3 cenderung lebih sedikit dibandingkan LLDIKTI lain seperti tercantum dalam gambar berikut:

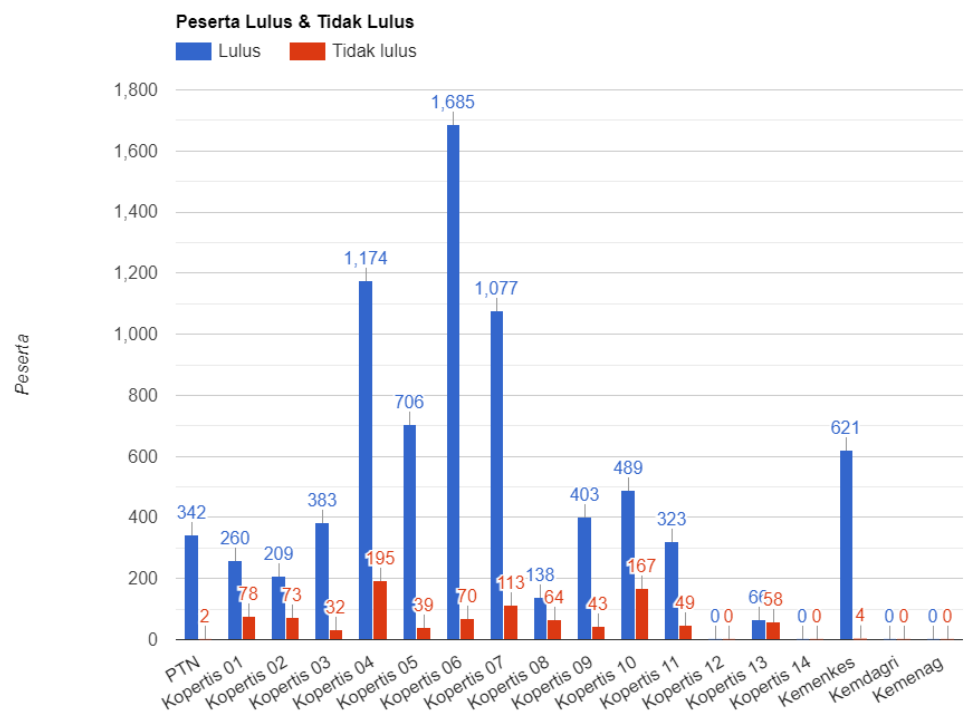

Gambar 2. Tingkat Kelulusan Uji Kompetensi Prodi Rekam Medis dan Informasi Kesehatan berdasarkan LLDIKTI

Sumber: Uknakes Kemdikbud 2021

Tingkat kelulusan Prodi RMIK UEU sendiri hampir setiap tahun selalu ada mahasiswa yang dinyatakan tidak kompeten seperti pada gambar berikut ini:

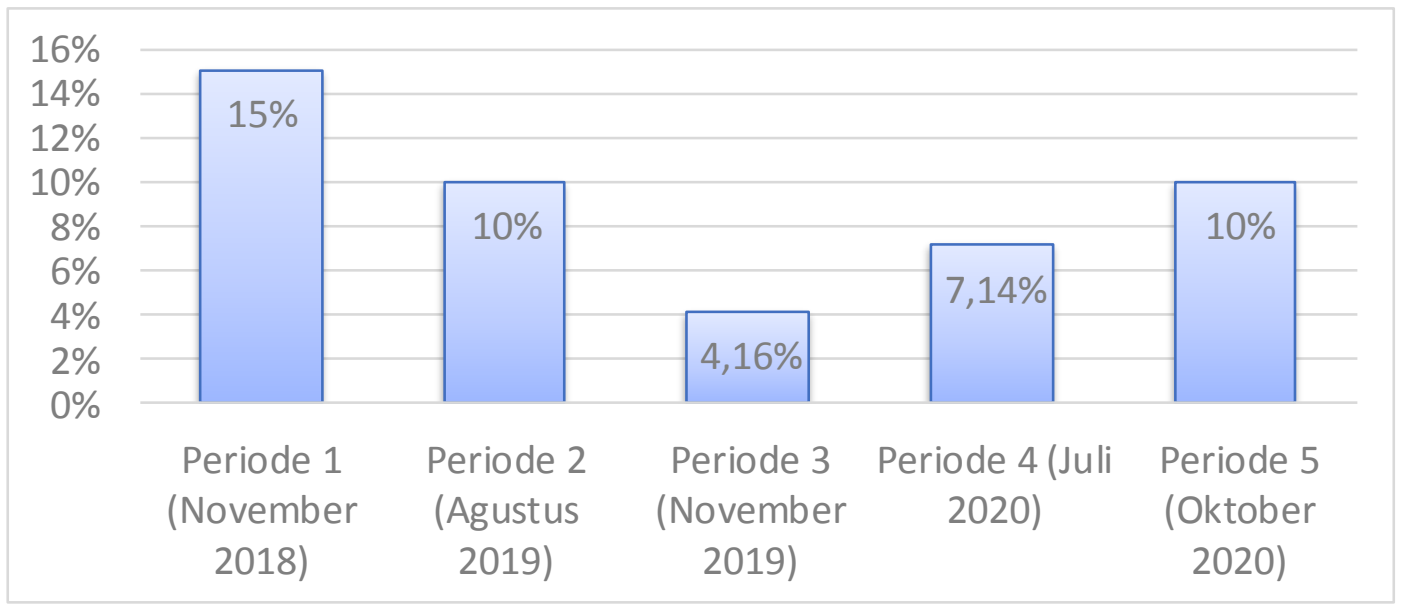

Gambar 3. Tingkat Ketidalulusan Uji Kompetensi Prodi Rekam Medis dan Informasi Kehatan UEU Sumber: Uknakes Kemdikbud 2021 
Berdasarkan data terlihat bahwa tingkat ketidaklulusan prodi RMIK UEU cenderung fluktuatif tiap periode.

Berdasarkan latar belakang diatas, perlu dilakukan sebuah upaya dari institusi pendidikan diantaranya pelatihan telaah soal uji kompetensi. Peserta dalam telaah soal adalah seluruh dosen D III dan D IV Perekam Medis dan Informasi Kesehatan di seluruh Institusi Pendidikan Indonesia dan praktisi RMIK. Materi yang diberikan adalah kompetensi esensial dari mata kuliah, penyusunan kriteria soal yang baik sehingga para dosen terbiasa membuat soal yang mengacu pada blue print uji kompetensi,dan dapat digunakan untuk UTS, UAS dan lain-lain.

\section{METODE}

Permasalahan yang dialami oleh dosen pada Prodi Rekam Medis dan Informasi Kesehatan saat ini adalah proses pembuatan soal uji kompetensi yang belum mengacu pada blue print uji kompetensi perekam medis dan informasi kesehatan serta pembuatan aplikasi uji kompetensi yang memiliki banyak kesulitan untuk try out di kampus masing-masing. Sehingga materi yang diberikan dalam pengabdian ini adalah Pemaparan Tehnik Telaah Soal Uji kompetensi serta praktek penggunaan aplikasi ujian online.

Pengabdian ini dilaksanakan melalui video conference (via aplikasi zoom) pada 15 Juli 2020 dikarenakan wabah pandemi Covid-19. Selain itu, kegiatan juga disiarkan secara live dalam platform youtube seperti gambar berikut ini:

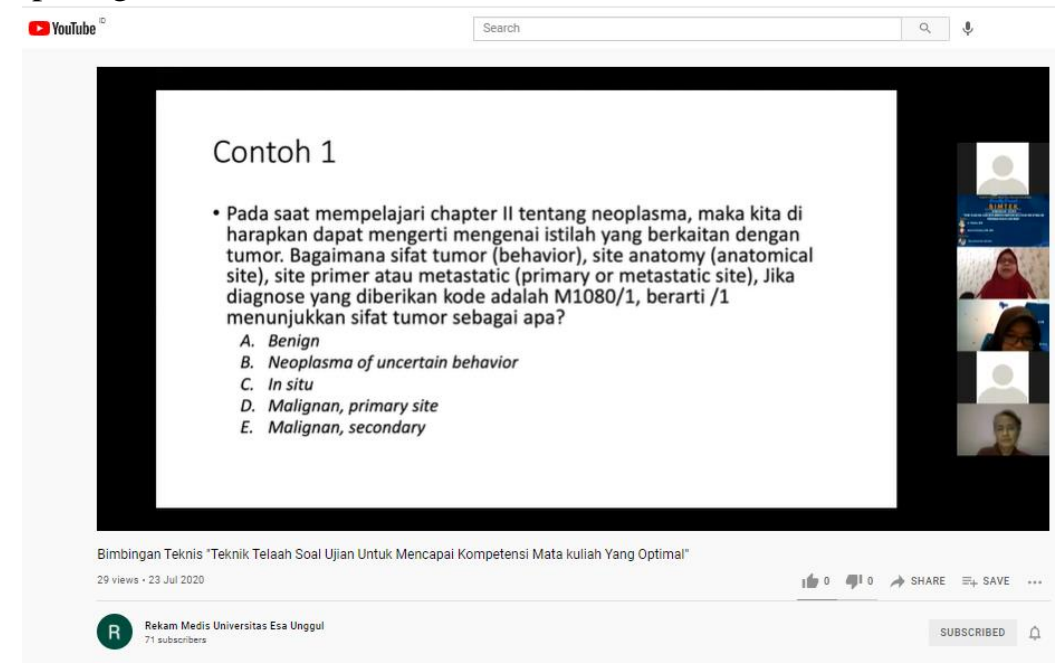

Gambar 4. Kegiatan Pelatihan Telaah Soal Ditampilkan Live Dalam Platform Youtube

\section{HASIL DAN PEMBAHASAN}

Setelah kegiatan pengabdian masyarakat tentang teknik telaah soal uji kompetensi perekam medis dan penggunaan aplikasi ujian online, maka dapat disampaikan hasil kegiatan sebagai berikut:

1. Kegiatan diikuti oleh 21 dosen Prodi Rekam Medis dan Informasi Kesehatan yang terdiri dari berbagai institusi di Indonesia diantaranya Apikes Bumi Husada, Politeknik Kesehatan Aisyiyah Banten, STIKes Mitra Husada Karanganyar, RSUD dr. Chasbullah Abdulmadjid Kota Bekasi, Apikes Widya Dharma Palembang, RSUD Ratu Zalecha, Universitas Esa Unggul, dan Stikes St. Elisabet Medan

2. 21 dosen yang mengikuti kegiatan pelatihan merupakan dosen yang mengampu berbagai macam mata kuliah yang diujikompetensikan diantaranya komunikasi efektif, manajemen rekam medis, statistik fasyankes, kodifikasi penyakit, patologi, terminologi medis, dan epidemiologi.

3. Distribusi provinsi peserta pelatihan seperti tersaji dalam table berikut ini: 


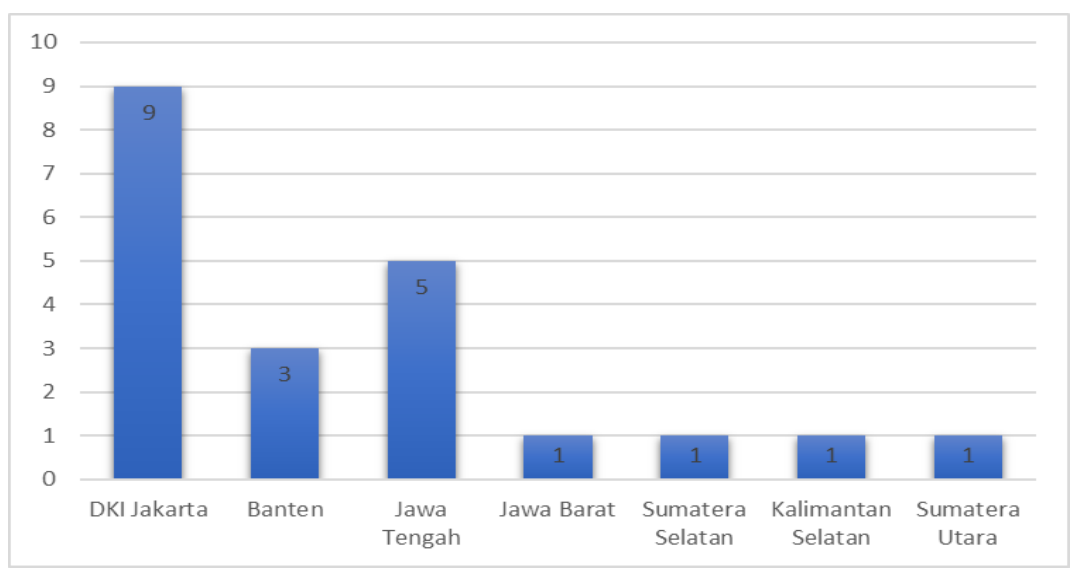

Gambar 5. Distribusi Peserta Pelatihan

Berdasarkan gambar 5 terlihat bahwa, 21 dosen peserta pelatihan menyebar dari beberapa provinsi di Indonesia diantara DKI Jakarta 9 dosen, Jawa Tengah 5 dosen, Banten 3 dosen dan sisanya Jawa Barat, Sumsel, Kalsel dan Sumut masing-masing 1 dosen.

Sebelum acara dilaksanakan, dosen-dosen peserta pelatihan diminta mengirimkan soal untuk ditelaah apakah soal sudah sesuai standar atau tidak. Pada saat acara dibahas masing-masing soal sehingga dapat dilakukan perbaikan oleh dosen yang bersangkutan. Telaah soal sering diremehkan oleh institusi pendidikan sehingga kurang perhatian. Padahal soal yang tidak ditelaah akan menyebabkan potensi soal ujian tidak valid (false positif atau false negatif). Telaah soal yang pertama dilakukan adalah kesesuaian dengan standar kompetensi atau capaian pembelajaran. Jika soal sudah relevan dengan standar kompetensi, maka selanjutnya dilakukan telaah struktur meliputi telaah vignette, telaah lead in, dan telaah option. Pemberian pelatihan dalam bentuk telaah soal sesuai dengan standar uji kompetensi menjadi penting dilakukan agar dalam membuat soal, dosen sudah mahir dan terbiasa menggunakan model soal standar uji kompetensi. Selain itu, intitusi pendidikan diharapkan sudah mengenalkan model standar uji kompetensi pada mahasiswa semenjak awal semester (Fitria et al., 2019). Selain itu mahasiswa juga diberikan bimbingan insentif menjelang diadakannya uji kompetensi (Choeron \& Metrikayanto, 2020).

Setelah dijelaskan mengenai telaah soal, materi selanjutnya tentang penggunaan aplikasi ujian online. Ujian secara online diperlukan karena pada masa pandemi, perkuliahan dilaksanakan secara full online. Sehingga aplikasi ujian online menjadi sangat dibutuhkan agar proses penilaian kepada mahasiswa tetap dapat dilaksanakan. Aplikasi ujian online yang disarankan adalah aplikasi testmoz. Testmoz merupakan sebuah media yang digunakan untuk membuat ujian dan quiz secara online. Aplikasi ini dirancang oleh Matt Johnson seorang mahasiswa dari Washington State University, Vancouver.

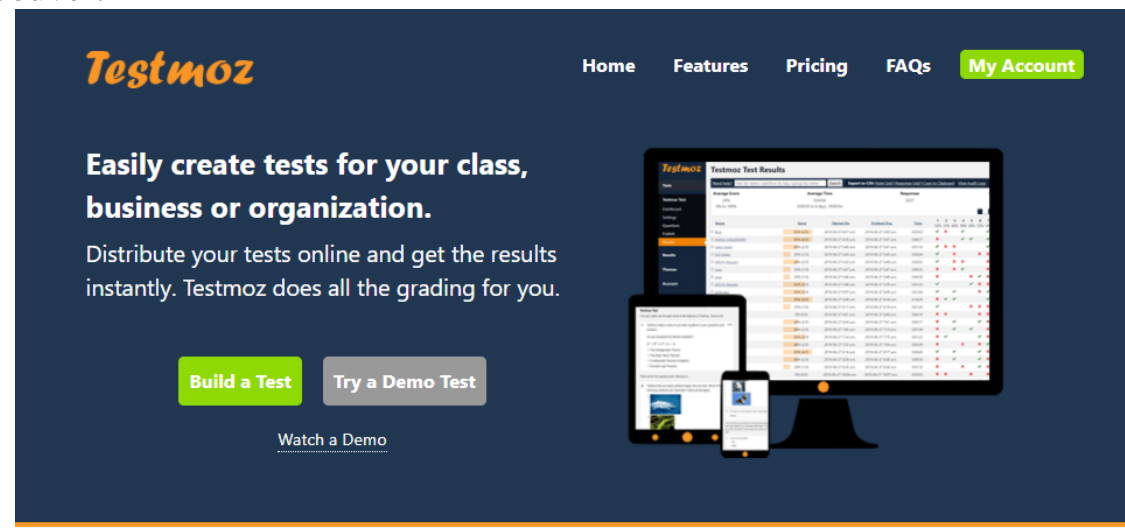

Gambar 6. Aplikasi Ujian Testmoz

Hal yang membedakan aplikasi Testmoz dengan lainnya diantaranya: mahasiswa yang akan mengerjakan ujian tanpa melakukan registrasi dan pembayaran, terdapat waktu yang berjalan mundur sebagai time limit saat mengerjaan soal, URL cukup mudah tanpa diperpendek, setting cukup mudah, model soal bervariasi (pilihan ganda, essay, fill in the blank, true/false, match), soal dan jawaban dapat di random/acak, soal dapat tampil per nomor atau keseluruhan, dapat digunakan 
pada bermacam gawai seperti hp, tablet dan desktop, low bandwith, dan dapat merekap nilai secara otomatis. Aplikasi testmoz sudah banyak digunakan oleh tenaga pendidik baik guru maupun dosen di era sekarang sejajar dengan Mentimeter, Quizizz, Survey Monkey, Cengage Now, EdPuzzle, Kahoot, Easy Test maker, Google Form, Excel dan, Quizlet(Sharef et al., 2019).

\section{SIMPULAN}

Kemampuan dosen dalam membuat soal dan menggunakan aplikasi uji online di era industry 4.0 dan masa pandemi covid-19 ini menjadi sangat penting dalam proses pembelajaran sehingga dosen lebih siap dan mahir dalam membuat soal sesuai standar uji kompetensi. Selain itu, kegiatan bimbingan intensif sebelum uji kompetensi serta penggunaan model soal uji untuk mahasiswa dari semester awal juga dapat menjadi faktor yang meningkatkan tingkat kelulusan mahasiswa rekam medis dalam mengikuti uji kompetensi. Keterampilan dosen setelah diberikan materi tentang teknik telaah soal uji kompetensi perekam medis dan penggunaan aplikasi ujian online meningkat. Sehingga pada masa mendatang dosen tidak mengalami kesalahan pada saat pembuatan soal.

\section{SARAN}

Saran yang dapat diberikan penulis terkait pengabdian masyarakat teknik telaah soal uji kompetensi perekam medis dan penggunaan aplikasi ujian online adalah, diharapkan kegiatan sejenis rutin dilaksanakan sehingga dosen-dosen muda yang belum pernah terpapar dengan pelatihan sejenis dapat mengikutinya. Selain itu seharusnya ada pre-test dan post test dalam rangka mengukur kemampuan dosen sebelum dan sesudah mengikuti pelatihan.

\section{UCAPAN TERIMA KASIH}

Penulis mengucapkan terimakasih kepada Prodi Rekam Medis dan Informasi Kesehatan Universitas Esa Unggul sehingga pelatihan teknik telaah soal uji kompetensi perekam medis dan penggunaan aplikasi ujian online dapat terselenggara dengan baik.

\section{DAFTAR PUSTAKA}

Andriaty, S. N., Findyartini, A., \& Werdhani, R. A. (2016). Studi Eksplorasi Kemungkinan Penyebab Kegagalan Mahasiswa dalam Uji Kompetensi Dokter Indonesia, Studi Kasus di Fakultas Kedokteran Universitas Abulyatama. Jurnal Serambi PTK, III(2), 1-12.

Choeron, R. C., \& Metrikayanto, W. D. (2020). Meningkatkan Kesiapan Uji Kompetensi Ners Melalui Bimbingan Intensif. Jurnal Ilmiah Keperawatan, 6(1).

Fitria, R., Serudji, J., \& Evareny, L. (2019). Persiapan Uji Kompetensi Bidan sebagai Exit Exam. Jurnal Ilmiah Universitas Batanghari Jambi, 19(1), 195-203. https://doi.org/10.33087/jiubj.v19i1.590

Kemenkes. (2013). Peraturan Menteri Kesehatan Republik Indonesia Nomor 55 Tahun 2013 tentang Penyelenggaraan Pekerjaan Perekam Medis.

Kemenkes. (2019). Peraturan Menteri Kesehatan No. 83 Tahun 2019 tentang Registrasi Tenaga Kesehatan (pp. 1-12).

Kemenkes. (2020). Keputusan Menteri Kesehatan tentang Standar Profesi Perekam Medis dan Informasi Kesehatan.

Nuryati, Santoso, D. B., \& Pramono, A. E. (2020). Kontribusi Faktor Kognitif terhadap Skor Kelulusan Uji Kompetensi. Jurnal Manajemen Informasi Kesehatan Indonesia, 8(1), 1-5. https://doi.org/10.33560/jmiki.v8i1.260

Presiden RI. (2014). Undang-Undang Republik Indonesia Nomor 36 Tahun 2014 Tentang Tenaga Kesehatan. In Menteri Hukum dan Hak Asasi Manusia Republik Indonesia.

Sharef, N. M., Ismail, A., Meng, G. Y., Zawawi, D., Romli, F. I., Udzir, N. I., Rashid, M. I. A. R., Khambari, M. N., Hod, R., Luan, W. S., \& Zakaria, M. H. (2019). Usage of Methods and Tools in Teaching and Learning: UPM Story. In S. Salam \& S. N. M. Mohamad (Eds.), International Conference on E-Learning 2019 (p. 82). 